\title{
The Preservation Ethic and the National Parks
}

\author{
Mountains Without Handrails: Reflections on the National \\ Parks. By Joseph L. Sax. Ann Arbor: The University of \\ Michigan Press, 1980. Pp. 152. \$10.00 (paper, \$5.95).
}

\section{Robert L. Rabin†}

More than a century ago, Congress took the unprecedented step of setting aside a vast tract of wilderness, the Yosemite Valley and its surroundings, as a federally protected nature preserve. With this action, the foundation stone was laid for what would become our system of national parks. In the ensuing decades, this country has experienced enormous growth in population, affluence, and technology. The national parks are not as inaccessible as they once were. We can tame the wilderness if it suits us, or we can strive to maintain the parks, within limits, as sanctuaries beyond the frontiers of urban society. The choice is ours to make.

In recent years, one finds perceptible indications of a departure from the strong preservationist tradition that long characterized national park administration. In its place, the park visitor is increasingly provided an experience that blends convenience with scenic observation. Rangers in Rocky Mountain National Park dispense information on steakhouses; the boat dock at Jackson Lake in the Tetons begins to resemble Belmont Harbor in Chicago; stores in Yosemite Valley are virtually indistinguishable from airport tourist shops; and Lower Yellowstone Falls is viewed from a platform adjoining a paved sidewalk and cement stairway.

A recently published volume on the national parks, Mountains Without Handrails, by Professor Joseph Sax, takes as its central concern the tension between these two conflicting philosophies of park management, preservation and conventional tourism - a tension that poses questions not just about the conveniences available to park visitors, but about the ambience and aesthetics of the scenic preserves themselves. These questions, in turn, raise fundamental issues about the imperatives of democratic principles in the context of public land management. This review of Sax's book will explore both the personal and the political dimensions of the preservation-

† Professor of Law, Stanford University. 
ist thesis.

Professor Sax argues that National Park policymakers do the public a great disservice by catering to their insecurities about nature. By doing so, park managers either permit domination of the natural setting, as in the instance of offroad vehicle use, or, even more typically, elicit a passive response, as in the classic case of the park visitor whose experience is limited largely to scenic turnouts and motorized loop trails. Worst of all, perhaps, when park philosophy cultivates an ambience of convenience facilities, the visitor is deprived of the opportunity to escape the familiarity and conformity that is an ubiquitous feature of ordinary life.

But Sax is not content to let his argument rest on the negative effects of taming the natural environment and diluting the park experience. Instead, he draws on a variety of sources, including a little-known Yosemite Report prepared a century ago by the eminent urban landscape architect Frederick Law Olmsted, to support his affirmative thesis that the unadulterated natural setting affords a singular opportunity for every park visitor-an opportunity to realize one's individuality through a sense of contemplation and an opportunity for close observation evoked by familiarity with the natural environment. ${ }^{1}$ Analyzing fishing, hunting, mountaineering and similar outdoor endeavors, Sax argues that central to each is a sense of satisfaction derived from the very process of engaging in the activity. In each case, he suggests, the true enthusiast regards the end result of the pursuit as secondary in importance. Once the participant is at ease in his milieu, a pervasive sense of harmony makes him attentive and responsive to detail in a highly individualistic way. ${ }^{2}$

Creating an agenda for the park visitor then-encouraging "tourism" by designating the viewing stations from which the Grand Canyon should be observed rather than allowing the visitor to create his or her own experience-is a monumental disservice. Driving, walking, or riding from one observation point to another, Sax suggests, is virtually certain to elicit a surface response, one that lacks the sense of absorption and accomplishment that is a salient characteristic of any activity truly worth undertaking. ${ }^{3}$

Thus, Sax counsels that lodgings, scenic areas, and float trips should

1. J. SAX, MOUNTAINS WITHOUT HaNDRAILS 18-26 (1980) [hereinafter cited by page numbers only].

2. Pp. 27-46.

3. Pp. 89-90, 111-12. 
reflect less of the technological clutter of our highly controlled everyday life. For the comfort-seeker, there is no shortage of convenience motels, scenic roadways, and leisure activities in the world outside the parks. Within their confines, however, Sax urges that we let the visitor find his or her own satisfactions.

Fundamentally, then, Sax is not arguing the preservation thesis on aesthetic grounds-that the parks need to be kept pure for those with the sensibility to appreciate natural beauty, or that wilderness is worth preserving for its own sake. Rather, his intention is to establish the congruence of his thesis with a version of the democratic tradition: that the people, all of us, deserve better than we get from government; that we possess in common an inner potential that can be more fully realized if we are, to some extent, forced back upon our own internal resources; and that fostering the contemplative spirit and the self-reliant impulse are exercises in democratic policymaking at its best. ${ }^{4}$

Sax's argument is made with subtlety and conviction; his book is both erudite and humane. My reservations about his thesis, on initial consideration, may be taken to be elitist in character. I would argue the contrary, however. I do harbor a fundamental skepticism about grounding the preservation ethic in a universalist appeal. But to argue, as I will, that the preservationist position has less than universal applicability, neither denigrates the life-style of others nor undercuts the democratic legitimacy of the claim.

Sax's underlying premise appears to be that a singular experience is available to everyone, not just the wilderness enthusiast, if the visitor is prepared to overcome the relatively modest physical inconvenience and hardship involved in experiencing the natural scenery of the national parks without the standard packaging of modern tourism. While Sax eschews detailed discussion of the experience itself, he seems to have in mind a kind of heightened awareness of one's surroundings-a vigilance of the senses and a serenity of the spirit-that arises out of absorption in untrammeled scenic splendor.

Precisely because this experience is available to everyone, Sax regards his version of the preservation ethic as an extension of democratic ideology to the world of scenic conservation. Instead of relying on the demands of a minority, whose preservation ethic is either based on their own special

4. Pp. 51-55, 103-05. 
claims to wilderness appreciation or their surrogate role as representatives of the scenic areas themselves, Sax seeks to locate his claim in a majoritarian tradition.

For a variety of reasons, I find this approach highly problematic. To begin with, I have grave doubts whether scenic exploration can bear the substantial burden of universal restorative and evocative power that Sax places upon it. The fact is that backpacking, river-running, mountainhiking, and even tent-camping are not activities for everyone. Contrary to Sax's view, my own experience has been that even though, as he asserts, one gets far more proficient at these activities with practice, they remain a substantial undertaking. Exploring the natural setting without recourse to customary conveniences involves a dramatic shift in tolerance and attitude. Climatic extremes, insects, and physical stress are constant companions. Even devoted enthusiasts of scenic exploration have to endure some measure of discomfort and inconvenience to experience the overriding satisfaction that comes from hiking down to the Colorado River in the Grand Canyon or reaching the Vogelsang Pass in Yosemite.

There is no reason to think that most park visitors would strike a similar balance between pain and pleasure, once cut loose from existing conveniences. In fairness to Sax, he does not argue that the only meaningful experience is one based on highly strenuous efforts such as one-day round trip hikes to the bottom of the Grand Canyon or to high mountain passes in Yosemite. Indeed, he explicitly argues the contrary-that each person's capacity should be the measure of his effort at scenic exploration. But this qualification threatens to drain his thesis of its vitality. One does not shift from tourist to explorer simply by abandoning the auto for one- or twomile hikes. If it were that easy to slip into the self-reliant and contemplative mode, there would be no substantial grounds for distinguishing between the preservationist appeal and conventional tourism. There are critical thresholds here that cannot be ignored, involving real abandonment of customary amenities and habits. And the aesthetic rewards, of course, are inextricably linked to the physical price of experiencing them.

It should come as no surprise that scenic exploration, in the realm of self-realization described by Sax, is likely to sustain a limited appeal. Consider a wide variety of other endeavors that offer some of the same rewards-a combination of aesthetic appreciation and serenity of spirit, a personal sense of unique enrichment. Most are found in the arts: poetry, classical architecture, painting, and chamber music, among other humanistic pursuits. None of these lasting forms of human expression has ever commanded broad popular appeal, and there is no particular reason to think that they will. To argue that everyone might potentially be enriched by exposure to Beethoven's late quartets smacks of a legal 
fiction-"constructive enrichment," we might label it-as the majoritarian underpinning for public support of chamber-music programming. Like most legal fictions, it is empirically suspect. What music lover doesn't number among his friends voracious readers or dedicated museum-goers, who derive serenity of spirit in their own way, and are temperamentally tone-deaf? Surely the same point applies to scenic exploration as a medium for self-enrichment. Some would prefer to pursue structuralist philosophy or medieval art, and would be largely indifferent to the wilderness experience.

It is one thing to argue the preservationist case as a universal therapeutic, a guide to fuller realization of individual potential. In doing so, Sax candidly confesses to being a moral reformer, concerned to convince the uninitiated that they are missing an opportunity for personal growth. ${ }^{5}$ One can differ with him and leave it at that. The more disturbing undercurrent in Sax's thesis is that politically the preservationist ethic can survive scrutiny only by establishing the universality of its credo. Otherwise, he appears to argue, a preservationist park management policy is incompatible with democratic tradition. The legions carrying the banner "Down with Elitism" will prevail.

In response, it is essential initially to dispel some confusion about "elitism," a label fraught with symbolic significance in the environmental field. In the present context, there is something odd about the claim of elitism, when we once make it concrete and observe its application. Consider a tent-camper at Signal Mountain campground in the Tetons, viewing the small-scale flotilla, shopping center, and tourist lodge that constitute his vista of Jackson Lake. ${ }^{6} \mathrm{He}$ and his backpacking cousins, preservationists on the whole, may not be able to claim the majoritarian status that would put charges of elitism to rest without more. Surely, however, in ordinary thought we do not equate elitism with all minority claims. Something seems initially amiss in labelling as elitist a desire for simplicity and naturalness of surroundings.

More commonly, the claim of elitism is linked to economic privilege in the environmental field, as in the case of industry pollution control standards or utility siting costs, which are thought to be borne disproportionately by lower income groups. ${ }^{7}$ But in the present context, the arguments of the convenience tourist are not those of the economically less-ad-

5. Pp. 103-04, 108-09.

6. The Signal Mountain campground overlooks a bevy of pleasure boats moored within easy reach of the dockside lodge. The overlook also takes in the lodge compound, which includes a cluster of stores and service buildings where one can purchase souvenirs and beachwear, have a cocktail and dine in the lounge, and dance and stroll on the boardwalk-style deck.

7. See, e.g., W. Tucker, Environmentalism and the Leisure Class, 255 HARPERS 49-56, 73-80 (Dec. 1977). 
vantaged. On the contrary, it is the naturalistic aspects of the national parks-the nominally-priced campgrounds and free trails, the picnic sites and unintrusive instruction in natural history-that constitute the principal attractions for the lower-income visitors to the parks.

Moreover, we normally associate elitism, in its negative sense, with a claim to privilege based on unwarranted imposition of one group's values upon another. In our Tetons setting we undeniably confront a classic instance of two conflicting attitudes towards recreational life style. Unless we rely purely on a head-count, however, the imposition issue must take into account the question of whether one recreational life-style can be more readily satisfied than the other through reasonable recourse to some accessible alternative areas. It hardly seems elitist for a substantial minority to argue that a contemplated use of public land that would extinguish their interest can be largely duplicated elsewhere.

While there is obviously only a single Jackson Lake and one range of Tetons, boating and scenic touring-including access to convenient dining and lodging, leisure shopping, and evening entertainment-are widely available in private resorts and accessible state-supported parkland. Harsh as it may sound, viewing the Tetons in passing-whether in a car, boat, or even on foot-is a thin experience that is nearly replicable elsewhere. ${ }^{8}$ By contrast, absorption in a natural setting is no easy matter. It takes time, space, and maximum freedom from the sights and sounds of the workaday world. It cannot be easily found outside the national parks.

Disposing of the claim of elitism, however, simply sets the stage for more substantial considerations. The more salient proposition suggested by Sax's thesis is that the preservationist can only maintain credibility by relying on a "democratic," that is, a universalist appeal. In my view, this position misconceives the nature of democratic institutions.

Take a typical arts activity maintained by a local community. The municipality that supports a children's theater does not do so on the premise that theatrical work-or, for that matter, merely theatrical attendance-will necessarily engage the interest or contribute to the personal development of a majority of the local populace. Assuredly, access is available to everyone. But that is quite a different matter from saddling the theater with the burden of demonstrating, even at the rhetorical level, its capacity to contribute to the personal enrichment of all the community youth.

Similarly, our public archives, art galleries, symphony halls, and botan-

8. Moreover, the preservationist position I am suggesting would not deny any group access to the parks, as distinguished from prohibiting services more in keeping with conventional tourist sightsecing. Like Sax, I argue only for a preservationist as opposed to a convenience philosophy of park management-not for a return to wilderness. 
ical gardens do not offer something for everyone, except in the sense that they are open to all on a nondiscriminatory basis. Our tastes in leisure are diverse, an agglomeration of discrete interests some of which may claim a large following - aspects of so-called mass culture-but many of which appeal to far smaller groups. Libertarians and other such opponents of public goods might raise an overriding question whether any of these activities, including those with majoritarian status, should be supported apart from voluntary contributions. The cautious arts administrator may feel a special compulsion to justify her own piece of the humanistic pie. But it would be a devastating shift in the way we collectively think about culture if the preserves set aside for various kinds of aesthetic, humanistic, and educational pleasure were each required to meet the test of satisfying some universal human need.

In my view, national park administration should rest on the unexceptional premise that these federal enclaves are an irreplaceable part of our national heritage. We establish libraries, museums, and performance halls as a medium for preserving, experiencing, and understanding our culture. Much of the music, art, and architecture of the past has disappeared, but we derive immeasurable satisfaction from the best of what has survived. In a rather different fashion, we value the skeletal remains, artifacts, and tools of vanished ancestral races for what they tell us about the evolutionary course of civilization. The same is true of the natural environment. Pristine wilderness was once everywhere. Only a vestige of the past remains to reinvoke the sense of physical struggle and scenic splendor that has played such a vital role in the shaping of the American character. We need not justify it as offering a universal restorative; it is worth preserving for those who will always find serenity, aesthetic satisfaction, solitude, or some form of transcendent experience in nature appreciation.'

Most likely, few would disagree with the proposition that the parks are an integral part of our common heritage. But does it follow that the preservationist claims of a vocal minority should be respected? Ultimately, the basis for rejecting the conventional tourist philosophy of park management must rest on the singular capacity of the national parks to provide a

9. It is possible to speak of these matters in two very different modes of discourse. In the discourse of political theory, democratic ideology is wholly consistent with a regard for the intensity of minority preferences. Alternatively, one can base protection of our heritage on the transcendent value of culture-entirely apart from aggregate votes in a political or economic marketplace. In either case, the interest we protect is not necessarily responsive to any universal human need. Still another tradition, which I put aside for present purposes, would counsel protection of natural objects in their own right. 
scenic experience that merges exploration with observation. Through the dimensions of time, space, and unsullied naturalness that only the parks provide, one comes to know the Tetons-rather than simply to view them.

It is not a question of whether the Hayden Valley in Yellowstone possesses some absolute capacity to enrich our lives that is missing in Central Park or Golden Gate Park; or whether McDonald Lake in Glacier has timeless aesthetic qualities that are not to be found in Chicago's Lake Michigan. It is the difference in experience that is critical rather than superiority on some point system. In taming wilderness, we diminish the range of human experience by eliminating a response to nature that is truly distinctive.

Correlatively, in protecting the wilderness experience, we simply acknowledge the pluralistic character of outdoor leisure activities. For those who get great satisfaction from an evening walk in a beautifully landscaped urban park or those who relish sailing and boating, a wide variety of recreational settings are available. For the relatively affluent vacationer who wishes to combine an outdoor setting with relaxation, leisure sports like golf or tennis, good dining and nighttime entertainment, there is no dearth of private resorts and lodges. For the casual nature lover, who seeks a mix of viewing pleasure and convenience, virtually every state has set aside adequate preserves to accommodate a variety of tastes.

What of the national parks then? In practical terms, how are they to be kept distinctive? In stressing the unique character of the wilderness experience, I do not mean to suggest an extreme preservationist ethic that would turn the parks into a backpackers' paradise. There are too many visitors who cannot or will not retreat into the back country, but who nonetheless feel a genuine reverence for the scenic values that the parks offer, to warrant a radical wilderness policy. But these scenic values are too fragile to withstand an ambience dominated by motorboats, pony rides, convenience shopping, and paved trails.

Tuolumne Meadows at Yosemite demonstrates that it is possible to maintain a relatively unadulterated natural setting and accommodate large numbers of visitors. The unobtrusive visitors' center provides trail information and a modest natural history display. The store and sandwich shop, a combined tent-like structure, offers the basic necessities that any visitor would require during a stay at the park, without falling prey to a souvenir shop mentality. While the campground bathroom facilities have modern plumbing, they do not have the all-night electricity that has turned restrooms into a blight on the late-hour tranquility of most park campgrounds. There are no paved trails, and no speedboats on Tenaya Lake. The visitor has to watch the road signs to find the rustic lodge facilities. In the evening, the campfire circle features a ranger talk and 
group singing; not the slide-show in an outdoor amphitheatre that has become an ubiquitous feature of national park campgrounds elsewhere.

If the Park Service installed electric lighting in the bathrooms at Tuolumne, it would not spell the downfall of the area. That is not my point. Rather, I am suggesting-and here again, Sax and I are on common ground-that, in the aggregate, a managerial philosophy geared to conventional tourism eventually undermines the wilderness values at the core of the park experience. ${ }^{10}$

I would join Sax, who has written a fine book, in hoping that before long the preservation ethic once again will be taken seriously by the Park Service. If I part company from him on the underpinnings of preservationist ideology, it is only to argue that the Park Service and its supporters need not rely on quasi-religious principles to buttress their claims for special protection of a fragile resource of inestimable value. If democracy is to have a civilizing influence it must exhibit a pluralism that safeguards the range of aesthetic and cultural values that make up our common heritage.

10. It is not even clear that the Park Service has, in most instances, been responding to its clientele. In many cases, my impression is that the Park Service has been pressed by the park concessioners to stimulate demand for convenience facilities, rather than acting in response to public criticism. 